\title{
Prologue
}

\section{Immunonutrition: An International Emerging Task Force}

The i-FINER (international Forum on Immunonutrition for Education and Research) group was created in 2007 starting a series of International Workshops on Immunonutrition, and continuing the series of international courses on immunonutrition since 1994. The i-FINER group has the objective to promote education and research in the interdisciplinary area that comprises the interaction between nutrition and immunology, through the advancement of its understanding, as well as through the publication and communication of its results; its mission is to provide conditions for expanding formation of human resources on immunonutrition, specifically concerning education and research; and its vision is to develop a longterm task force to yield a novel vision of nutrition and immunological requirements for a health policy, including governmental policies.

On this base, the $6^{\text {th }}$ International Workshop on Immunonutrition was held in Palma de Mallorca (Spain) in October $\left(15^{\text {th }}-17^{\text {th }}\right), 2012$. Twenty six oral communications and sixty six posters were presented which focused primarily on nine key topics: 1) Exercise Immunology and Nutrition; 2) Functional Foods and Bioactive Compounds; 3) Methodology on Immunonutrition; 4) Micronutrients; 5) Probiotics and Prebiotics; 6) Diet Related Fats; 7) Translational and Integrative Approach to Immunonutrition; 8) Obesity-related Inflammatory Diseases; and 9) Childhood Obesity and Inflammation. This last session was shared with the organization of the $22^{\text {nd }}$ Workshop of the ECOG (European Childhood Obesity Group) that was held between the $17^{\text {th }}$ and $19^{\text {th }}$ October, 2012 in Palma de Mallorca (Spain).

Near one hundred and fifty participants attended the workshop coming from 24 countries all over the world, as follows: Algeria, Argentina, Brazil, Denmark, Finland, France, Georgia, Ghana, Greece, Hungary, Iran, Italy,
Mexico, Nigeria, Portugal, Romania, Serbia, Spain, Sweden, Switzerland, The Netherlands, United Kingdom, USA, and Venezuela.

As the President of this event, I would like to thank the unconditional support of the i-FINER Board members (Philip C. Calder, Mireille Dardenne, Laurence Harbige, Gabriela Perdigón, Wilson Savino, Nevin Scrimshaw, Nora Slobodianik, Liseti Solano, Noel Solomons, Roxana Valdés, Paveen Yaqoob), Ada de las Cagigas, Andreu Palou, Catalina Picó and Josep Tur (local committee), my research group (Ligia Esperanza Díaz, Alina Gheorghe, Sonia Gómez-Martínez, Aurora Hernández, Jorge Mujico, Esther Nova, Fátima Pérez de Heredia, Tamara Pozo, Ana Veses, Julia Wärnberg, Belén Zapatera), Sandra Chargy, director of Master Congresos as the technical secretariat. The important involvement of Bayer, Coca-Cola and Danone, and the participation of Biosearch Life, Centro de Información Cerveza y Salud (Information Centre on Beer and Health), Central Lechera Asturiana, Mead Johnson, and Merck were very welcome and appreciated, as well as the endorsement of the Spanish Nutrition Society, the Argentinian Society of Clinical Research, the Asociación de Celiacos de Madrid (Association of Celiacs from Madrid), and very especially the Nutrition Society and the Proceedings of the Nutrition Society.

The $7^{\text {th }}$ International Workshop on Immunonutrition is planned to be held in Bari. Emilio Jirillo and Mauro Serafini will be in charge of the organization of the event.

In memoriam of the friends who believed in this project and supported our dreams in the dissemination of the immunonutrition up to the end (Nevin Scrimshaw, Javier Romeo, Manuel Antonio de Pablo and Quico Roses).

Ascensión Marcos (on behalf of the i-FINER group) 